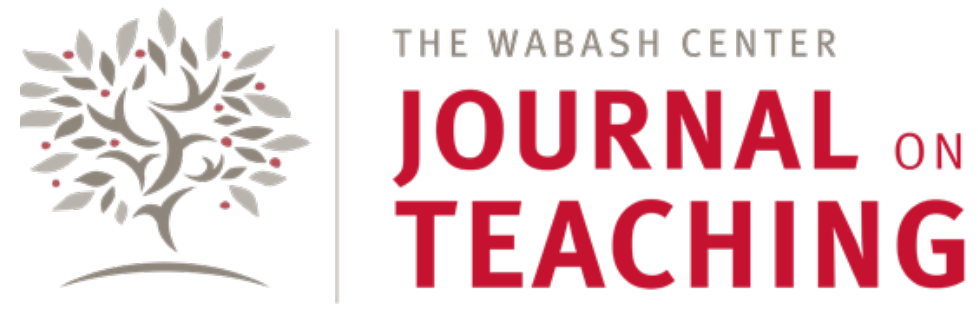

ARTICLE

\title{
Combining Accessibility and Pedagogical Effectiveness in a Hybrid Theological Education Program: A Case Study
}

\author{
Andrew R. H. Thompson \\ School of Theology, the University of the South (Sewanee)
}

\begin{abstract}
As of 2017, the Association of Theological Schools had seen an increase in online course enrollment of 200 percent over ten years. It is therefore worth exploring in some depth the potential challenges and strengths of online and hybrid programs. This article describes one hybrid online-residential program, the Alternative Clergy Training at Sewanee (ACTS) program at the School of Theology at the University of the South, familiarly known as Sewanee. Based on the experience of this program and contemporary research on the strengths of online and hybrid programs, it is argued that hybrid learning has significant advantages in its own right, perhaps especially for those who may be considered "hybrid clergy," the deacons and bivocational priests for whom the program was designed.
\end{abstract}

\section{KEYWORDS}

online learning, hybrid, bivocational, distance learning, accessibility

As of 2017, the Association of Theological Schools had seen an increase in online course enrollment of 200 percent over ten years (Scharen and Miller 2017, 3). Online and hybrid programs make theological education more accessible to a broad range of students, and some argue that they are at least as effective as traditional face-to-face programs (Scharen and Miller 2017, 3). For many, this shift may be at best an unwelcome necessity, as increases in accessibility are presumed to come at the expense of sacrifices in pedagogy. Yet others present online and hybrid programs as exciting new learning contexts, with their own distinctive strengths and weaknesses.

In this article, I will explore some disadvantages and advantages of a hybrid program of theological education as reflected in one such program, Alternative Clergy Training at Sewanee (ACTS). In particular, I argue for the suitability of a hybrid program to what may be thought of as hybrid ministries: the diaconal and bivocational priestly ministries that this program is specifically designed to serve. ${ }^{1}$ Thus, after a brief overview of the program, I will consider this notion of "hybridity" and the implications it has had for how we have designed this particular program. These illustrations highlight some of the strengths and weaknesses of hybrid learning as suggested by our own experience and borne out by broader research. The strengths and weaknesses of such programs give the lie to the assumption noted above that what is good about hybrid learning is necessarily what is most

1 It bears emphasizing that in applying the term "hybrid" to these ministries, I in no sense mean to diminish them or present them as something other than fully legitimate orders of ministry (just as my description of hybrid education will emphasize that it is not a lesser form of theological education, but an important model in its own right). I only wish to highlight the formal similarities between these kinds of ministry and this form of education. 
similar to a traditional classroom - that is, the face-to-face component. Taken together, the insights gleaned from considering the ACTS program viewed in light of contemporary research on online and hybrid learning indicate that this type of program has significant advantages, perhaps especially for deacons and bivocational priests.

I make these observations not as an expert in online or hybrid pedagogy, but rather as an educator and administrator seeking to incorporate current research in a practicable and effective manner. In addition to directing the program since 2017, I teach the "Christian Ethics and Moral Theology" module, and have taught the "Ministry in Contemporary Society" module in the past. Accordingly, the challenges and learnings I offer here reflect both perspectives, that of director and that of instructor. In particular, I emphasize what I will describe as the counterintuitive character of some features of this style of learning in the hope that others in a similar position and with similar presuppositions might come to shed those and to appreciate more fully the distinctive strengths of hybrid programs.

Most of the data specific to the ACTS program come from anecdotal or informal observation, supplemented by formal student evaluations where possible. One of my first actions as director was to initiate online student evaluations of the modules and the program, in order to assess student satisfaction and pedagogical effectiveness. Since these evaluations have only been in place for one cycle of modules as of this writing, we have very limited longitudinal data at this point. Nonetheless, the evaluations have been helpful in confirming, clarifying, and expanding upon feedback from more informal sources.

\section{Overview of the Program}

The ACTS program is a hybrid online-residential theological education curriculum at the School of Theology at the University of the South (familiarly known as Sewanee) intended for persons preparing for part-time bivocational priestly ministry and for the diaconate. It is situated in an Episcopal Seminary that is, in turn, part of a university owned by dioceses of the Episcopal Church. The program works with Episcopal dioceses to identify students for whom a full-time residential MDiv program is not a feasible option-for example, individuals with jobs that they will maintain during their future ministry and from which they therefore cannot resign, as well as students preparing for diaconal ministry, which is traditionally unpaid in the Episcopal Church. Since its start as the Non-Degree Theological Studies Program in 2014, enrollment in the program has ranged from three to sixteen. The diaconal aspect of the program was formally added in 2019, although students and dioceses had previously used the program for that purpose. The overarching goal of the program is to provide students with the academic preparation to begin their ministries effectively; the students' dioceses are expected to attend to other aspects of their preparation, such as spiritual formation and field education. A more focused teaching goal is to enable students to apply their learning in their particular ministry contexts, which are typically small, often rural, churches, and to reflect on and better appreciate the distinctive calling of their bivocational priestly or diaconal ministry.

The program combines intensive residential education with online distance learning. Each course (or "module," in the nomenclature of the program) begins with a week-long residential period, followed by several months of distance learning, and concludes with another week-long residency. Two modules run concurrently, and there are two terms per year, beginning in January and in June, for a total of four modules per year. The program comprises eight modules, based on the areas of theological education named in the Canons of the Episcopal Church: "Old Testament and Preaching," "New Testament and Preaching," "Theology, Including Sacramental Theology," "History, Including Episcopal Church History and Polity," "Christian Ethics and Moral Theology," "Pastoral Theology," "Prayer Book and Liturgy," and "Ministry in Contemporary Society." In place of "Pastoral Theology," diaconal students take a module called "Diakonia" that covers the history, theology, and practice of the diaconate. Students may enroll in the program at any point, and can take whatever modules they or their diocese deem necessary.

\section{Hybrid Education for Hybrid Clergy}

To a certain extent, the design and administration of this program reflect an intuition that bivocational priests and deacons might be particularly well served by a hybrid program of this nature. Of course, the initial motivation for establishing a hybrid program was necessity: students who expect to continue in their current vocations are often unable to commit to full-time residential study, but we were unwilling to sacrifice the residential aspect of theological education completely (which will be discussed further below). Nonetheless, in the time since I became director of the program, the faculty and I have worked to strengthen the program based on a sense that the formal similarity between hybrid study and the "hybridity" of serving in 
a bivocational context might be a strength for the program to build on. Bivocational priests and deacons, in different ways, exercise ministries that integrate two different contexts: they perform specific functions within the institutional church, such as celebrating sacraments or fulfilling particular roles in the liturgy, and they have, as part of their distinctive vocation, a call to carry out their ministerial work in the wider world. The task of integrating these two contexts into one coherent ministry is a central part of these vocations. In many ways this parallels the structure of hybrid programs that combine a face-toface component that is more directly situated within a traditional seminary structure (both literally and figuratively) with a distance-learning component more directly engaged with students' home contexts. Here too, the task of integrating the two contexts is essential.

One thing that many of us involved in the program have observed in our modules is that students in the ACTS program show a high level of interest and facility in drawing connections between their professional and ministerial contexts and the curriculum relative to their residential MDiv counterparts. It is one of the joys of teaching in this program: because students are already involved in lay or diaconal ministry, a secular vocation, or both, they continually relate the subject being addressed to their own context. So, for example, a lawyer and veteran regularly brought his experiences in those areas to bear on discussions of questions in ethics such as truth-telling and just war theory. A practicing psychologist, a nurse, and a hospital chaplain in the same class enriched discussions of medical ethics. This is not simply a matter of drawing on personal experience in class discussions, as most students do. ACTS students are mindful of their unique position as bivocational ministers, and express this in their observations and discussions, often prefacing questions with allusions to it. A representative example would be something like, "As someone who will be both a priest and a lawyer/doctor/teacher, how will I be able to speak about this in both contexts?"

Our sense was that a hybrid program could build on this distinctive positioning. By educating students in both places-their home context and a residential seminary - the program could be designed to maximize this kind of situated reflection. We have attempted to do this in a number of ways. First, we have encouraged faculty to assign projects or practical assignments based in a student's ministry, rather than essays, as course assignments. Depending on a student's context, they may choose to submit a sermon, newsletter article, or Sunday school curriculum. Such assignments invite students to make clear connections between course readings and the needs of their ministry contexts; they also, of course, allow students to produce something that will be of immediate use to them, and get feedback from instructors to improve the submitted material. When these assessments occur during a module, rather than after its conclusion, they can also illuminate subsequent class topics and discussions.

Some modules lend themselves readily to this engagement between course material and ministry. For example, during the distance portion of my "Christian Ethics and Moral Theology" module, which focuses on applied issues in ethics, students present case studies from their own ministries that engage the particular ethical topics of the class. After a focused discussion of the assigned texts, students take turns reflecting on sexual ethics, war and peace, economics, and environmental ethics with examples drawn from their experiences in schools, churches, and a prison. Other students and I have opportunities to ask questions and add reflections; as instructor, it is often necessary for me to make possible connections with the readings clearer or to focus discussion on the more pertinent elements of the case. All the participants in the discussion reflect on ways the presenter might approach or respond to the challenges or problems they face. This use of case studies has helped students see more clearly how topics in moral theology relate to matters of direct import to their ministries, and has brought reflections from their ministries to bear on their consideration of the course material.

Another module where this aspect of distance learning is particularly salient is "Ministry in Contemporary Society." In the most recent iteration of that module, during the distance learning portion, students submitted a variety of assignments designed to engage their communities and ministry contexts. One of the major assignments was a stewardship sermon prepared with the students' contexts in mind. And for much of the content of that module, students were invited to propose topics and questions that emerge from their own ministries. The module also encourages students to look beyond their own contexts to engage topics: students are asked to submit a recorded podcast interview with a community leader outside their immediate (Episcopal) faith tradition, and to visit a place of worship of another religious tradition and submit a written reflection on the experience.

These attempts to facilitate learning in students' contexts during the distance portion are framed by the residential periods at the beginning and end of each module. These residential portions further strengthen the distinctive hybridity of the program in two ways. First, especially in the opening residential portion, these periods establish a strong learning community. 
During residential portions (a total of four weeks per year), students are in class together for approximately four hours per day. They form relationships that foster collaborative learning and will help sustain their online discussions.

Second, the residential periods provide important content that can help students engage their ministry contexts. The chronology of some modules is designed around this goal. For example, some modules move more contemporary or applied topics to the online portion so they can take advantage of the residential portion for establishing fundamentals at the beginning and addressing additional themes at the end, incorporating students' experiences and reflections from their contexts. Students can master key topics or themes in face-to-face meetings, apply those ideas in their particular contexts and reflect on them together online, then return to bring those reflections together with new themes or considerations. These kinds of changes can make the overall trajectory of the module seem haphazard, so it is important to communicate clearly with students how the various elements of the course relate to one another.

For example, in “Christian Ethics and Moral Theology," a typical progression in a traditional classroom setting might move from sources and principles of ethics to topics of applied ethics such as sexuality and the environment. This reflects a relatively common idea of how ethics works-beginning with sources and articulated principles then moving toward application to timely issues. The hybrid module, by contrast, begins with sources and types of ethics (during the first residential period) and concludes with principles for ethics (during the concluding residential period), with applied ethics during the intervening distance period. Thus students are introduced to theoretical and methodological concerns during the first residential period, when they have more opportunity to engage with the instructor. They also establish a learning community that will support their reflections during the distance portion. Both of these features help facilitate meaningful reflection and discussion on contemporary applied topics during the distance portion, where students have the opportunity to relate the topics in applied ethics to situations in their own lives and ministries. These reflections in context then inform discussion of additional themes when students return for the concluding residential component.

Taken together, these efforts integrate online learning both with students' daily lives, on the one hand, and with the residential component, on the other. They also relate to the program's specific goal of preparing students for bivocational ministry in small congregations, and of helping them see the distinctive strengths of this form of ministry. At its best, bivocational ministry highlights the relationship between the church and the world, inviting reflection on mission and evangelism in and with local communities. Bivocational ministers can at times be particularly well equipped to facilitate this reflection, since they operate professionally both in and out of the church. By using the distance-learning portion of the ACTS program to invite students to integrate course content with their ministry contexts, we build on the program's distinctive identity.

\section{The Challenge and Promise of Hybrid Learning}

I have presented what I take to be the potential strengths of a hybrid program for bivocational ministry based on the formal similarity between the hybridity of this ministry and the hybridity of the program. The support for this idea is mostly anecdotal: informal feedback from students, professors' observations, and written assignments suggest that the students do engage the modules in this way, reflecting back and forth from context to seminary, and that they find this aspect of the program to be beneficial. Formal research would be needed to make a more convincing argument that hybrid programs do indeed work well for training bivocational clergy. In our case, small sample size and the lack of longitudinal data from before my time as director have limited my ability to make such an argument.

These reflections on the suitability of a hybrid program for bivocational clergy also indicate some strengths and weaknesses of hybrid programs more generally, features that are in fact supported by broader research. While this research was not a part of our initial intuitions about the structure of the program, it does support many of the choices that were made. More importantly, being aware of these particular features of hybrid education-what works, and why it works-enables our program and others like it to enhance the strengths and mitigate the weaknesses of hybrid theological education.

This is especially important because some of these strengths and weaknesses may at first seem counterintuitive, at least if one approaches hybrid education with assumptions like the ones I initially brought to it. I assumed, like many others, that the strengths of hybrid programs would lie mostly in the residential portion-that is, in the aspect of the program most similar to traditional classrooms-and that the weaknesses would be primarily related to the distance portion. In other words, I viewed hybrid theological education as derivative of traditional face-to-face learning, and assumed it would be effective to the extent to which it replicated or approximated that model. However, our experience has shown, and research bears out, that this is not 
the case. While distance learning through online media certainly presents some initial challenges in program design and execution, the more substantial challenges and strengths of a hybrid program are more evenly distributed between the two components of the modules.

I begin these considerations where the program begins, with the residential component. While this is the part most similar to a traditional face-to-face classroom, with many of the same characteristics, it also presents its own strengths and challenges that go beyond those of its more traditional counterpart. Delamarter and Brunner point out (2005) that hybrid courses can actually increase student-teacher interaction and class connectivity when compared to traditional face-to-face classes. This increased connectivity begins in the initial face-to-face sessions, where a learning community can be established through intentional practices of socialization (Delamarter and Brunner 2005, 152). In the case of the ACTS program, as noted above, this residential component begins and ends each of the modules. During residential portions (a total of four weeks per year), students are in class together for approximately four hours per day. This is supplemented by corporate worship, shared meals, and programmed fellowship. Interestingly, students have also been proactive in initiating social activities, organizing meals together, welcoming and orienting new students to campus, and planning excursions. They thus take advantage of the opportunity provided to “jump-start” (in Delamarter and Brunner's [2005] words) the learning community during this intensive period. This emphasis on connectivity carries over into effective online interactions that nourish the community of learning through the distinctive features of online communities (which will be discussed below).

There are also, however, distinctive challenges to the residential component of a hybrid program. A demanding class schedule that is sustained for two weeks at a time leaves students and instructors exhausted. Students have less time to read and process material during residential periods; they typically have to read most of their assignments beforehand, which may not be most conducive to comprehension. While the total number of contact hours for the term (including the distance portion) is roughly equal to many of the residential MDiv courses, faculty may feel the need to cover as much material as possible in the limited residential time, which may feel rushed as a result. It is particularly important to be aware of these challenges precisely because this is the aspect of a hybrid program that feels most familiar to faculty and students. It is tempting to approach the residential portion as if it were simply a standalone face-to-face course. Delamarter and Brunner note the importance of redesigning this component of a course with an eye to its particular characteristics and to integrating the two aspects of a hybrid course into a single unified course (2005, 151-52).

Our experience in the ACTS program reveals a further counterintuitive feature of the intensive residential component. In a program designed to make theological education more accessible, four weeks of residency per year may be challenging, if not prohibitive, for many students with full-time jobs and families, even when those weeks are divided between June and January. Yet evaluations indicate that most students appreciate the demanding nature of the program. Moreover, this relatively high residential requirement allows students to experience some crucial aspects of seminary life: participation in worship and community life and the formation of a supportive learning community. Thus, in addition to the pedagogical benefits and drawbacks of the residential period of a hybrid program, the difficulty of meeting the residential requirements of the program has proven to have pedagogical impact in itself, forcing students to prioritize and plan carefully.

If it seems at first that the drawbacks to a hybrid program would be mostly concentrated in the online portion, the aspect most dissimilar to a traditional classroom, then research and experience again counter this assumption. There are certainly significant start-up costs to the online classroom, in terms of acclimating to the technology, establishing consistency, and navigating a different conversational format (Delamarter and Brunner 2005, 155). Literature on online learning is insistent that in whatever format, online discussions require adept and consistent faculty facilitation and moderation (Delamarter and Brunner 2005, 151; Bach, Haynes, and Smith 2007, 112). Nonetheless, when designed and facilitated properly, online classrooms prove to have distinctive advantages that not only approximate those of a traditional classroom, but indeed may actually improve upon them.

Research indicates that students generally experience the quality of discussion and engagement in online courses as being higher than in face-to-face courses (Scharen and Miller 2017, 32). The effectiveness of online learning in this area may be greatly dependent on the mode of learning: synchronous (real-time interaction, such as a videoconference or chat) versus asynchronous (delayed-time interaction such as the use of a message board). While synchronous modes of interaction have been shown to be more conducive to building a strong sense of community, asynchronous interactions tend to be more intellectual in character, at least for the most challenging types of content (Oztok et al. 2013, 89). Again, the quality of the discussion is highly dependent on the instructor's active involvement in facilitating it, in all modes of interaction. In some cases, shy students have indicated that they feel more able to participate in such discussions, and some students feel that online discussions mitigate the perception of racial or cultural divides sometimes experienced in face-to-face interactions (Bach, Haynes, and Smith 2007, 112). It seems likely that these effects would be most significant in non-visual forms of synchronous or asynchronous interaction, such as online chats or message boards. 
Thus it seems that a combination of regular asynchronous interactions and synchronous video-conferences is most able to take advantage of the pedagogical potential of online learning (Oztok et al. 2013, 92-93).

Our program currently centers on synchronous videoconferencing for its online component. Given the relatively small size of the classes and the user-friendliness of the platform, video conference discussions have proven accessible and effective, based on student evaluations. In my module, these sessions usually combine a short background lecture accompanied by visual aids, followed by discussion of related texts. Students participate readily and converse with the instructor and one another comfortably, and discussions have been substantive and engaging. One student noted the effectiveness of the lectures and visual aids in this context. The effectiveness of the platform does not completely overcome the difficulties of online discussions, and some students remain bothered by the "awkwardness" of the online medium. To these difficulties are added the same challenges that confront any class discussion: some students dominate, others participate less. In an online setting, it may be more difficult for the instructor to monitor and respond to such discrepancies. However, the program's small class size mitigates this difficulty somewhat. At the same time, some past modules (including an earlier version of my own) have relied on asynchronous methods of engagement, and as noted above, there may be strong reasons to return to these in some contexts, or to combine synchronous and asynchronous interaction in a single module.

Again, it is essential to design a hybrid course as an integrated whole, combining online and residential portions thoughtfully. In the ACTS program, as I have described, some modules have done this by scheduling more applied or practical content during the online portion. Some research seems to confirm that this indeed builds on the distinctive strengths of online learning: online settings are more conducive to students' integration of coursework with work or ministry. The literature refers to this as the contextual aspect of hybrid courses. Delamarter and Brunner describe it thus: "these programs can encourage students to view the situation as a theological education being brought into their lives as opposed to putting their lives on hold while they do a theological education" $(2005,134$; cf. Scharen and Miller 2017, 32). They note that this aspect of such programs not only affects students' integration of their learning outside the classroom, but it also transforms the discussion within the classroom: "it can change the nature of the interactions that characterize the learning environment: from theoretical discussions about possible future scenarios in ministry, to the enrichment of ministry already in progress" (Delamarter and Brunner 2005, 154). Moreover, when the course is structured in the way I have described with applied issues during the online portion, then the reduced anxiety around participation and the diminished perception of racial or cultural divides that some students report in online forums may make discussion of challenging or controversial topics more productive in that setting. That said, research is mixed on the effectiveness of synchronous versus asynchronous interaction in these regards, and so the means we use to emphasize the distinctive capacities of online learning will have to be carefully considered.

\section{Accessibility and Pedagogy}

Based on feedback from our main constituents, students and their bishops, we believe the structure of the ACTS program takes advantage of the pedagogical, social, and spiritual benefits of a residential seminary while also capitalizing on many of the strengths of online learning. In terms of learning outcomes, data from General Ordination Exams (GOEs) of the Episcopal Church suggest that the program has been educationally satisfactory by that particular standard, though not as effective as a residential MDiv program. ${ }^{2}$ It will be necessary to implement additional evaluation standards more specific to the goal of this program-that is, preparing clergy for effective bivocational and diaconal ministry-to measure the program's educational effectiveness more directly (cf. Scharen and Miller 2017, 33).

More significantly, however, this program continues to build on one of its guiding intuitions: the sense that hybrid learning might be particularly well-suited to what might be called the hybridity of bivocational priests and deacons. Modules are designed to highlight the respective benefits of residential and online learning in order to maximize students' opportunities to integrate classroom learning with their ongoing work and ministries. By maintaining a relatively high residency requirement, we not only provide more opportunities to enhance learning and group cohesion and offer students an experience of a residential seminary community, we also challenge students to commit fully to their theological formation and to plan and prioritize accordingly. Additionally, by emphasizing the contextual aspect of hybrid learning, we enhance both the online and the residential components of the program, and facilitate practical learning in students' ministry contexts. As has been noted, there are areas where we must be more intentional about structuring modules to play to these strengths; like many institutions, we are still coming to understand and realize the full potential of online learning.

2 GOE test takers are scored as "Proficient" or "Non-Proficient" in each of six canonical areas. In 2016, 2017, and 2018 combined, a majority of NDTS students were rated "Proficient" in at least five of the six areas (sample sizes for individual years are too small to be useful taken separately). 
What all of this makes clear is that hybrid programs do not necessarily require sacrificing effectiveness in order to increase accessibility. Hybrid and online learning are not simply better-or-worse approximations of a face-to-face classroom; they are new pedagogical environments that present new opportunities as well as new challenges that can enhance learning opportunities. Delamarter and Brunner put it poetically: with hybrid and online learning, "colors on the teaching palette multiply" (2005, 150). What is more, these new environments and new color palettes may be precisely what is needed to prepare leaders in a changing church. What could be better than non-traditional education programs to prepare clergy to imagine the non-traditional forms of church that are becoming more and more necessary? While learning Bible and church history, students in hybrid programs are also practicing novel ways of interacting, of facilitating conversation, and of nurturing community. As both hybrid education and hybrid clergy become more common, the new color palettes they bring to ministry may provide the flexibility and creativity the church will so urgently need.

\section{BIBLIOGRAPHY}

Bach, Shirley, Philip Haynes, and Jennifer Lewis Smith. 2007. Online Learning and Teaching in Higher Education. Maidenhead, England: McGraw-Hill Education.

Delamarter, Steve, and Dan Brunner. 2005. "Theological Education and Hybrid Models of Distance Learning." Theological Education 40 (2): 145-64. https://www.ats.edu/uploads/resources/publications-presentations/theological-education/2005-theological-education-v40-n2.pdf.

Oztok, Murat, Daniel Zingaro, Clare Brett, and Jim Hewitt. 2013. "Exploring Asynchronous and Synchronous Tool Use in Online Courses." Computers \& Education 60 (1): 87-94. https://doi.org/10.1016/j.compedu.2012.08.007.

Scharen, Christian, and Sharon Miller. 2017. “(Not) Being There: Online Distance Education in Theological Schools.” Auburn Studies 23 (Fall). https://auburnseminary.org/report/not-being-there/.

\section{ABOUT THE AUTHOR}

Andrew R. H. Thompson is Visiting Assistant Professor of Theological Ethics at the School of Theology, the University of the South (Sewanee). He writes primarily about environmental ethics and theology. He is also director of the Alternative Clergy Training at Sewanee (ACTS) program and of the Sewanee Ministry Collaborative. 
